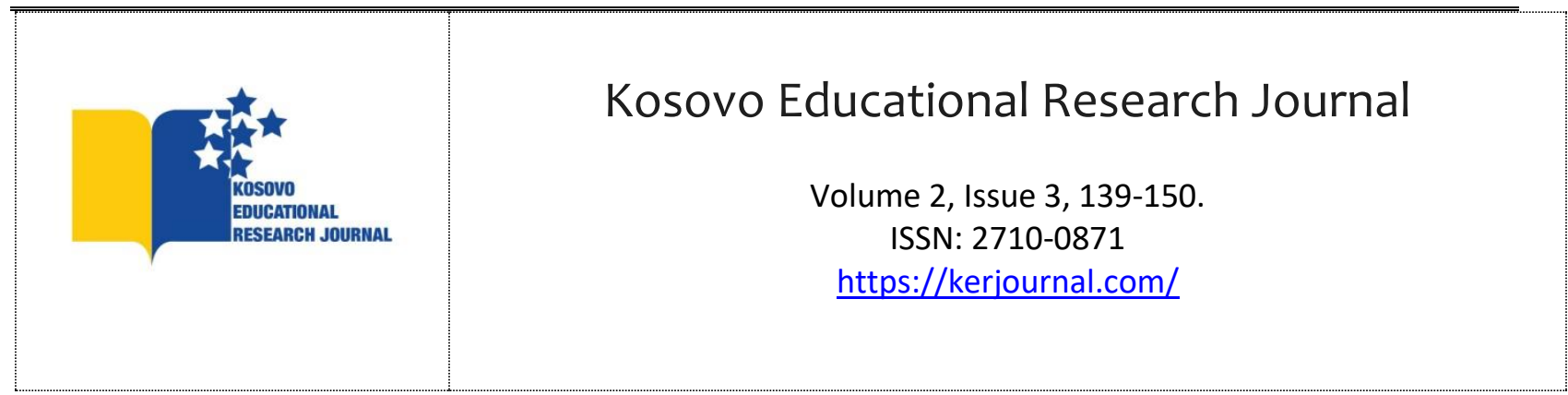

\title{
Yaratıcı Drama Destekli Öğretimin Öğrencilerin Akademik Başarısına Etkisi
}

Sevgi MAZREK

Prizren Ukshin Hoti Üniversitesi

ÖZET: Eğitimde yaratıcı drama; her hangi bir konuda, doğaçlama, rol oynama gibi tekniklerden yararlanarak, bir grupla ve grup üyelerinin birikimlerinden, yaşantılarından yola çıkarak canlandırmalar yapmaktır. Eğitim öğretim farkındalık ve gelişim alanlarında yaparak yaşayarak deneyimlemesine ortam yaratan bir yöntemdir. Her bireyin kendine has öğrenme biçimi vardır. Okul öncesi yaşlardan başlayarak herkesin katılabileceği yaratıcı drama, yöntem ve araç olarak pek çok alanda kullanılabilmektedir. Yaratıcı drama; Eğitim öğretim farkındalık ve gelişim alanlarında insanların yaparak yaşayarak, deneyimlemesine ortam yaratan bir yöntemdir. Günümüzde yalnızca bireyin gözlenebilen davranışlarını, öğrenme ürünü olarak kabul eden davranış̧ı yaklaşım yerine, öğrenmenin bireysel bir süreç olduğunu, bilginin bireyden bireye doğrudan aktarılmayacağını, her bireyin kendi bilgi ve anlamını kendi zihinsel sürecinde inşa edebileceğini kabul eden oluşturmacı (yapılandırmacı) yaklaşım ön plana çıkmıştır. Bu gelişmelerin doğrultusunda 2004 yılında eğitim sistemimiz yapılandırmacı yaklaşım felsefesi temel alınarak hazırlanmıştır. Yapılandırmacı Yaklaşım, bir bireyin nasıl anladığını ve öğrendiğini açıklayan felsefi bir yaklaşımdır. Araştırmanın genel amacı; yaratıcı drama destekli öğretimin öğrencilerin akademik başarısı üzerine etkisinin incelenmesidir. Bu araştırmanın genel amacını, 2020/2021 eğitim-öğretim yılı Prizren, Mamuşa ve Priştine illerinde bulunan ilkokullarda görev yapan sınıf öğretmenlerinin bazı demografik özelliklere göre yaratıcı drama öğretimin öğrencileri akademik başarısına etkisi konusunda inceleme yapılmıştır. Bu araştırmada Yaratıcı Drama Destekli Öğretimin Öğrencilerin Akademik Başarısına Etkisi açısından incelemek amacıyla tarama çalışması olarak tasarlanmıştır.

Bu araştırma nicel araştırma yönteminde tasarlanmıştır. Nicel araştırma yaşanan olguları ve olayları nesnelleştirerek gözlemlenebilir duruma getiren araştırmalardır. Nicel araştırma sayısal araştırma olarak da bilinmektedir. Araştırmanın örneklemi belirlenirken amaçsal örnekleme ile araştırmanın yapılacağı okullar seçilmiş ve bu okullardan Türkçe eğitim veren, Prizren, Priştine ve Mamuşa Belediyesindeki okullarındaki sını öğretmenlerine uygulanmıştır. 
Araştırma Prizren Belediyesinde 5 devlet ilkokulunda (Abdyl Frashëri, Mati Logoreci, Motrat Qiriazi, Mustafa Baki,ve Emin Duraku), Mamuşa Belediyesindeki “Anadolu İlköğretim Okulunda" ve Priştine Belediyesindeki “Elena Gjika” ilkokulunda 46 Öğretmen ile görüşme yapılmıştır.

Anahtar Kelimeler: Yaratıcı Drama, Öğrencilerin Akademik Başarısına Etkisi.

To cite this article: Mazrek, S. (2021). Yaratıcı Drama Destekli Öğretimin Öğrencilerin Akademik Başarısına Etkisi. Kosovo Educational Research Journal, 2(3). 139-150.

\section{GİRIŞ}

Eğitimde yaratıcı drama; her hangi bir konuda, doğaçlama, rol oynama gibi tekniklerden yararlanarak, bir grupla ve grup üyelerinin birikimlerinden, yaşantılarından yola çıkarak canlandirmalar yapmaktır.

Eğitim öğretim farkındalık ve gelişim alanlarında yaparak yaşayarak deneyimlemesine ortam yaratan bir yöntemdir. Her bireyin kendine has öğrenme biçimi vardır. Okul öncesi yaşlardan başlayarak herkesin katılabileceği yaratıcı drama, yöntem ve araç olarak pek çok alanda kullanılabilmektedir.

Yaratıcı drama; Eğitim öğretim farkındalık ve gelişim alanlarında insanların yaparak yaşayarak, deneyimlemesine ortam yaratan bir yöntemdir.

Akademik başarı, eğitimdeki önemli çalışma alanlarından birisi olarak görülmektedir. Üstündağ ( 1996) yaratıcı dramayı, bireylerde estetik bir sanat anlayışı oluşturması nedeniyle eğitim alanı, yaşantının ortaya çıktığı süreci açıklaması nedeniyle disiplin ve bireylere bilgi, duygu ve devinimleri kazandırması nedeniyle öğretim yöntemi olarak nitelendirmektedir. Yaratıcı dramanın önemli temsilcilerinden Heathcote ( 1984) yaratıcı dramayı, yaşam deneyimini arttırma Courtney (1989), zihindeki düşünceleri eyleme dönüştürme olarak görmektedir.

Yratıcı drama, öğrencilerin duygu, düşünce ve davranışlarını gelişmesini (Somers, 1994), bağımsız düşünmelerini ve duygularını ayrımına varmalarını sağlar (Ward, 1960).

\section{YÖNTEM}

\section{Araştırmnın Modeli}


$\mathrm{Bu}$ araştırma nicel araştırma yönteminde tasarlanmıştır. Nicel araştırma yaşanan olguları ve olayları nesnelleştirerek gözlemlenebilir duruma getiren araştırmalardır. Nicel araştırma sayısal araştırma olarak da bilinmektedir.

\section{Evren ve Örneklem}

Evren; araştırma sonuçlarının genellenmek istendiği elemanlar bütünüdür (Karasar,2010). Araştırmanın evreni; Kosova'da Türkçe Eğitim veren ilkokullarda, bu okullarda çalışan Sınıf Öğretmenlerin den oluşmaktadır. Örneklem; belirli bir evrenden, belirli kurallara göre seçilmiş ve seçildiği evreni temsil yeterliliği kabul edilen küçük kümedir (Karasar,2010).Araştırmanın örneklemi belirlenirken amaçsal örnekleme ile araştırmanın yapılacağı okullar seçilmiş ve bu okullardan Türkçe eğitim veren, Prizren, Priştine ve Mamuşa Belediyesindeki okullarındaki sınıf öğretmenlerine uygulanmıştır. Araştırma Prizren Belediyesinde 5 devlet ilkokulunda (Abdyl Frashëri, Mati Logoreci, Motrat Qiriazi, Mustafa Baki ve Emin Duraku), Mamuşa Belediyesindeki “Anadolu İlköğretim Okulunda” ve Priştine Belediyesindeki "Elena Gjika” İlkokulunda 46 öğretmen ile görüşme yapılmıştır.

\section{BULGULAR}

$\mathrm{Bu}$ bölümde, araştırmada ele alınan amaçlar doğrultusunda elde edilen verilerin istatistiksel analizleri sonucunda elde edilen bulgularına yer verilmiştir. Bulgular, amaçların diziliş sırası dikkate alınarak sunulmuştur.

\section{Araştırmaya katılan öğretmenlerin ders verdikleri sınıf dağılımları}

Araştırmada birinci sınıfa ders verdikleri öğretmenlerin sayısı 8 (17.4\%), ikinci sınıfta ders verdikleri öğretmenlerin sayısı 9 ( $19.6 \%$ ), üçüncü sınıfta ders verdikleri öğretmelerin sayısı 10 (21.7\%), dördüncü sınıfta ders verdikleri öğretmenlerin sayısı 9 (19.6\%), beşinci sınıfta ders verdikleri öğretmenlerin sayısı $10(21.7 \%)$ oluşmaktadır. Bu veriler aşağıdaki tablo 1'de sunulmuştur.

Tablo 1. Araştırmaya katılan öğretmenlerin ders verdikleri sınıf dağılımları

\begin{tabular}{c|r|r}
\hline & Frekans & \multicolumn{2}{|c}{ Yüzde } \\
\hline 1 Sınıf & 8 & 17.4 \\
\hline
\end{tabular}




\begin{tabular}{l|r|r}
\hline 2 Sınıf & 9 & 19.6 \\
\hline 3 Sınıf & 10 & 21.7 \\
\hline 4 Sınıf & 9 & 19.6 \\
\hline 5 Sınıf & 10 & 21.7 \\
\hline Total & 46 & 100.0 \\
\hline
\end{tabular}

\section{Araştırmaya katılan öğretmenlerin cinsyet dağılımları}

\begin{tabular}{r|r|r}
\hline & Frekans & \multicolumn{2}{|c}{ Yüzde } \\
\hline Kadın & 39 & 84.8 \\
\hline Erkek & 7 & 15.2 \\
\hline Total & 46 & 100.0 \\
\hline
\end{tabular}

Yukarıda 2. tabloda görüldüğü gibi 46 öğretmenlerin 39 katılımcıların kadın, 7 katılımcıların ise erkek oluşturduğu görülmektedir

\section{Araştırmaya katılan öğretmenlerin yaş dağılımları}

Öğretmenlerin yaş dağılımları bakıldığında araştırmaya katılan 46 öğretmenlerden: 22-30 yaş arası öğretmenlerin sayısı 2 (4.3\%), 30-40, 40-50 yaşlar arasındaki öğretmenlerin sayısı 16 (34.8\%), diğer yaş arası öğretmenlerin sayısı 12 (26.1\%) oluşturmaktadır. Bu veriler aşağıdaki tablo 3 'te sunulmuştur.

Tablo 3. Araştırmaya katılan öğretmenlerin yaş dağılımları

\begin{tabular}{l|c|c}
\hline & Frekans & Yüzde \\
\hline
\end{tabular}




\begin{tabular}{r|r|r}
\hline $22-30$ & 2 & 4.3 \\
\hline $30-40$ & 16 & 34.8 \\
\hline $40-50$ & 16 & 34.8 \\
\hline Diğer & 12 & 26.1 \\
\hline Total & 46 & 100.0 \\
\hline
\end{tabular}

\section{Öğrencilerinizin Drama yolu ile girişkenliği gelişiyor mu?}

\begin{tabular}{llrr}
\hline & & Frekans & \multicolumn{2}{c}{ Yüzde } \\
\hline Valid & Evet & 38 & 82.6 \\
\cline { 2 - 4 } & Hayır & 2 & 4.3 \\
\cline { 2 - 4 } & Kararsızım & 6 & 13.0 \\
\cline { 2 - 4 } & Total & 46 & 100.0 \\
\hline
\end{tabular}

Yukarıda Tablo 4'te görüldüğü gibi öğretmenlerin \%82.6 (38 kişi) evet cevabını vermektedirler. \%4.3 (2 kişi) hayır ve \%13.0 (6 kişi) ise kararsızım cevabını vermektedirler.

\section{Öğrencilerinizin drama yoluyla iletişim kurma becerileri artıyor mu?}

\begin{tabular}{|c|c|c|}
\hline & Frekans & Yüzde \\
\hline Evet & 43 & 93.5 \\
\hline Kararsızım & 3 & 6.5 \\
\hline Total & 46 & 100.0 \\
\hline
\end{tabular}


Yukarıda Tablo 5'te görüldüğü gibi öğretmenlerin \%93.5 (43 kişi) evet, \%6.5 (3 kişi) ise kararsızım cevabını vermektedirler.

\section{Öğrencilerin drama yöntemi ile problem çözme ve karar verme yetisi gelişiyor mu?}

\begin{tabular}{|c|c|c|}
\hline & Frekans & Yüzde \\
\hline Evet & 36 & 78.3 \\
\hline Hayır & 1 & 2.2 \\
\hline Kararsızım & 9 & 19.6 \\
\hline Total & 46 & 100.0 \\
\hline
\end{tabular}

Yukarıda Tablo 6'da görüldüğü gibi öğretmenlerin \%78.3 (36 kişi) evet, \%2.2 (1 kişi) hayır ve \%19.6 ( 1 kişi) ise kararsızım cevabını vermektedirler.

\section{Öğrencileriniz Yaratıcı ve hayal gücüne dayalı roller üretebiliyor mu?}

\begin{tabular}{|c|c|c|}
\hline & Frekans & Yüzde \\
\hline Evet & 33 & 71.7 \\
\hline Hayır & 3 & 6.5 \\
\hline Kararsızım & 10 & 21.7 \\
\hline Total & 46 & 100.0 \\
\hline
\end{tabular}

Yukarıda Tablo 7' de görüldüğü gibi öğretmenlerin \%71.7 (33 kişi) evet cevabını, \%6.5 (3 kişi) hayır ve \%21.7 (10 kişi) ise kararsızım cevabını vermektedirler. 


\section{Öğrencileriniz dramaya katılırken işbirliği içerisinde mi?}

\begin{tabular}{l|r|r}
\hline & Frekans & \multicolumn{2}{|c}{ Yüzde } \\
\hline Evet & 41 & 89.1 \\
\hline Hayır & 1 & 2.2 \\
\hline Kararsızım & 4 & 8.7 \\
\hline Total & 46 & 100.0 \\
\hline
\end{tabular}

Yukarıda Tablo 8' de görüldüğü gibi öğretmenlerin \%89.1 (41 kişi) evet cevabını, \%2.2 (1 kişi) hayır ve \%8.7 (4 kişi) ise kararsızım cevabını vermektedirler.

\section{Öğrencileriniz Grupla birlikte duygularını ve düşüncelerini tartışabiliyor mu?}

\begin{tabular}{ll|r|r}
\hline & Frekans & \multicolumn{2}{|c}{ Yüzde } \\
\hline Valid & 39 & 84.8 \\
\cline { 2 - 4 } & Evet & 1 & 2.2 \\
\cline { 2 - 4 } & Kayır & 6 & 13.0 \\
\cline { 2 - 4 } & Kararsızım & 46 & 100.0 \\
\hline Total & & \\
\hline
\end{tabular}

Yukarıda Tablo 9'da görüldüğü gibi öğretmenlerin \%84.8 (39 kişi) evet cevabını, \%2.2 (1 kişi) hayır ve \%13.0 (6 kişi) ise kararsızım cevabını vermektedirler.

Konuştuğu dili kullanma yeteneği gelişiyor mu?

\begin{tabular}{r|r|r}
\hline & Frekans & \multicolumn{2}{|c}{ Yüzde } \\
\hline Evet & 43 & 93.5 \\
\hline
\end{tabular}




\begin{tabular}{l|r|r}
\hline Hayır & 1 & 2.2 \\
\hline Kararsızım & 2 & 4.3 \\
\hline Total & 46 & 100.0 \\
\hline
\end{tabular}

Yukarıda Tablo 10’da görüldüğü gibi öğretmenlerin \%93.5 (43 kişi) evet cevabını, \%2.2 ( 1 kişi) ise hayır ve \%4.3 (2 kişi) kararsızım cevabını vermektedirler.

\section{Somut-soyut arasında ilişki kurabiliyor mu?}

\begin{tabular}{|c|c|c|c|}
\hline & & Frekans & Yüzde \\
\hline \multirow[t]{4}{*}{ Valid } & Evet & 40 & 87.0 \\
\hline & Hayır & 1 & 2.2 \\
\hline & Kararsızım & 5 & 10.9 \\
\hline & Total & 46 & 100.0 \\
\hline
\end{tabular}

Yukarıda Tablo 11' de görüldüğü gibi öğretmenlerin \%87.0 (40 kişi) evet cevabını, \%2.2 ( 1 kişi) ise hayır ve \%10.9 (5 kişi) kararsızım cevabını vermektedirler.

\section{Kendisini ve gruptaki diğer kişileri olumlu bir biçimde eleştiriyor mu?}

\begin{tabular}{lr|r|r}
\hline & \multicolumn{2}{|c|}{ Frekans } & \multicolumn{2}{|c}{ Yüzde } \\
\hline Valid & 30 & 65.2 \\
\cline { 2 - 4 } & Evet & 2 & 4.3 \\
\cline { 2 - 4 } & Kayır & 14 & 30.4 \\
\cline { 2 - 4 } & & 46 & 100.0 \\
\hline
\end{tabular}


Yukarıda Tablo 12’de görüldüğü gibi öğretmenlerin \%65.2 (30 kişi) evet cevabını, \%4.3 ( 2 kişi) ise hayır ve \%30.4 (14 kişi) kararsızım cevabını vermektedirler.

\section{Drama etkinlikleri öğrencilerin akademik başarısına etkisi oluyor mu?}

\begin{tabular}{ll|r|r}
\hline & \multicolumn{2}{|c|}{ Frekans } & \multicolumn{2}{|c}{ Yüzde } \\
\hline Valid & 43 & 93.5 \\
\cline { 2 - 4 } & Evet & 1 & 2.2 \\
\cline { 2 - 4 } & Kayır & 2 & 4.3 \\
\cline { 2 - 4 } & Total & 46 & 100.0 \\
\hline
\end{tabular}

Yukarıda Tablo 13' te görüldüğü gibi öğretmenlerin \%93.5. (43 kişi) evet cevabını, \%2.2 ( 1 kişi) ise hayır ve \%4.3 (2 kişi) kararsızım cevabını vermektedirler.

\section{Sonuç ve Öneriler}

Yaratıcı Drama Eğitim öğretim farkındalık ve gelişim alanlarında yaparak yaşayarak deneyimlemesine ortam yaratan bir yöntemdir. Her bireyin kendine has öğrenme biçimi vardır. Okul öncesi yaşlardan başlayarak herkesin katılabileceği yaratıcı drama, yöntem ve araç olarak pek çok alanda kullanılabilmektedir.

Yaratıcı drama; Eğitim öğretim farkındalık ve gelişim alanlarında insanların yaparak yaşayarak, deneyimlemesine ortam yaratan bir yöntemdir. Yaratıcı drama bir süreçtir ve yaratıcılık için çeşitli düşüncelere açık olması gerekmektedir. Ayrıca çok boyutlu zekanın ortaya sunulmasıdır. Yaratıcı drama, çocukların gönüllü olarak katıldığı, kendi yaşantılarından yola çıkarak doğaçlama ve rol oynama tekniklerinin kullandığı bir süreçtir. Yaratıcı drama, kendine özgü teknikler ve çocukların dili olan oyunu da kullanarak toplumsal yaşam becerilerine yönelik etkinliklerin yapılmasıdır. Bu durumda çocuklar işbirliğine dayalı öğrenme, problem çözme, aktif öğrenme gibi öğrenci merkezli yöntemlerden oluşmaktadır. Aynı zamanda tüm derslerden yararlanabilecek bir etkinlik türüdür. 
Araştırmamızda öğretmenlerin bilgi ve tutumlarını ele alarak: yaratıcı drama destekli öğretimin öğrencilerin akademik başarısına etkisi konusunda inceleme yapılmıştır. Araştırma Prizren, Mamuşa ve Priştine illerinde sınıf öğretmenleriyle yapılmıştır. Bu araştırmada toplam 46 öğretmen katılmıştır (39 kadın, 7 erkek).

Bu konuda öğretmenlerimize "Dramaya aktif olarak katılıyor mu?"' sorusuna \%93.5 katıldıklarını belirlemiştirler diğer \%2.2 öğretmenler grubu ise katılmadıklarını vurgulamıştır. Bu büyük yüzdenin sebebi günümüzde çocukların kendileri yaparak yaşayarak öğenme biçiminde gönüllü olarak katıldıklarını görüyoruz. Bu süreçte öğrenciler kendileri yaparak aynı zamanda yaşayarak edindikleri bilgirler daha fazla akıllarında kalmaktadır. Hayır diyen kısım ise bazı öğretmenler 1. Sınıfta dramayı kullanmadıkları için hayır cevabını vermektedirler.

Bu konuda öğretmenlerimize sorduğumuz soru “ Dramaya katılımda istekli mi? ” sorusuna \%95.7 evet, \%2.2 hayır,ve \%2.2 kararsızım cevabını vermiştirler. Dramaya katılımda büyük yüzdenin sebebi öğrenciler etkinliklerden yararlandıklarını görüyoruz.

Sorulan soruda " Drama dersine yönellik olarak olumlu bir tutuma sahip mi? " sorusuna öğretmenlerin \%82.6 evet cevabını, \%2.2 katılmıyorum ve \%15.2 kararsızım cevabını vermektedirler.

Sorulan soruda " Doğaçlama oyunları oynamaya istekli mi? "' sorusuna öğretmenlerin \%71.7 evet cevabını, \%6.5 hayır ve \%21.7 kararsız kaldıklarını vurguluyor. Bu soruda öğrencilerin doğaçlama oyunlarına katıldıklarını görüyoruz. Doğaçlama oyunları öğrencilerin içinden geldiği gibi doğal bir rol yapmasıdır. Çoğunluk olarak öğrenciler bu oynları oynamakta istekli. Diğer yandan da katılmadıklarını ve kararsız kaldıklarını görüyoruz. Bu aşamalarda bazı öğrenciler her hangi bir oyunlarda oynamak istemezler. Diğer bir soruda " İletişim kurma becerileri artiyor mu? ", sorusuna öğretmenlerin \%93.5 evet cevabını vermişler, \%6.5 katılmadıklarını vurgulamışlar.Bu yüzdenin sebebi öğrenciler işbirliği içerisinde olduklarında çeşitli fikirler ortaya çıktığında her öğrencinin iletişim kurma becerisi gelişiyor.

Öğretmenlere sorduğumuz soruda ، Dramaya katılırken işbirliği içerisinde mi? ", sorusuna öğretmenlerin \%89.1 evet cevabını, \%2.2 katılmadıklarını, ve \%8.7 kararsız kaldıklarını vurgulamışlar. Bu sorunun cevabına öğrenciler etkinlikler sırasında arkadaşlarıyla birlikte işbirliği içerisinde bulunuyor. Drama sırasında öğrenciler birbiriyle yardım alarak çeşitli fikirler ortaya 
çıkarak öğrenciler daha fazla işbirliği içerisinde olduklarını görüyoruz. Diğer yandan bu soruya katılmadıklarını görüyoruz. Bunun sebebi bazı öğrenci arkadaşları ile pek fazla iletişm kuramaz. Bu soruda kararsız kaldıklarını vurgulamışlar.

Öğretmenlere sorduğumuz soruda "Grupla birlikte duygularını ve düşüncelerinin tartı̧̧abiliyor mu?" sorusuna öğretmenlerin \%84.8 evet cevabını, \%2.2 katılmadıklarını, ve \%13.0 kararsız kaldıklarını vurgulamışlar. Büyük yüzde ile çoğunluk olarak evet cevabını vermişler. Öğrenciler grupla beraber oldukları zaman duyglarını ve düşüncelerini daha fazla aktarabiliyor. Grupla birlikte yapılan etkinlikler her kişiden farklı farklı fikirler ortaya çıkar ve daha kolayca sonuca ulaşılır. Diğer yandan kararsız kaldıklarını görüyoruz. Bunun sebebi her öğrenci aynı değildir, bazısı tek başına yapılan etkinliklerden hoşlanır. Gurpla birlikte yapılan çalışmalarda kendisini kolayca ifade edemez.

Öğretmenlere sorduğumuz soruda "Bireysel yaratıcıllı̆ı̆ı ve hayal gücünü drama ortamında tümüyle aktarabiliyor mu? " sorusuna öğretmenlerin \%73.9 evet cevabını, \%4.3 katılmadıklarını, ve \%21.7 kararsız kaldıklarını görüyoruz. Bu sorunun cevabına çoğunluk olarak katıldıklarını görüyoruz. Drama ortamında öğrenciler oyunlar esnasında yaparak yaşayarak aniden kendiliğinden davranabiliyor. Diğer yandan katılmadıklarını ve kararsız kaldıklarını görüyoruz. Bunun sebebi bazı öğrenciler yaratıcıllğııı karşı tarafa ifade edemez.

Öğretmenlere sorduğumuz soruda "Sizce drama etkinlikleri akademik başarısına etkisi oluyor mu? " sorusuna öğretmenlerin \%93.5 evet cevabını, \%2.2 hayır ve \%4.3 kararsızım cevabını vermektedirler. Bu sorunun cevabına büyük bir yüzdeyle evet cevabını vermektedirler. Drama öğrencilerin hayal gücünü, eleştirel düşünme, iletişim kurma becerileri ve daha bir çok şey öğrecilerin akademik başarısına etkisi olduğunu görüyoruz. Diğer yandan katılmadıklarını ve kararsız kaldıklarını görüyoruz. Bazı öğrenciler drama etkinliklerinde yararlanmaz ve bu yüzden öğrencinin akademik başarısına etkisi olmaz.

Araştırma sonuçları yaratıcı dramam öğretimin akademik başarıyı arttırmada etkili olduğunu göstermektedir. Bu nedenle farklı öğretim programlarında yaratıcı drama yöntemine yer verilerek öğrencilerin akademik başarılarının artırılması sağlanabilir. Yaratıcı drama yönteminin etkili olabilmesi için doğru uygulanması gerekir. Bunun sağlanması amacıyla yaratıcı drama zorunlu bir 
ders olarak öğretmen eğitimi programlarına konulabilir. Drama yöntemini bilmeyen öğretmelere hizmet içi eğitim programlarında drama alması teşvik edilebilir.

\section{KAYNAÇA}

Ulubey, Özgür, and Çetin Toraman. "Yaratıcı drama yönteminin akademik başarıya etkisi: bir meta-analiz çalışmasi/The effect of creative drama on students' academic achievement: A metaanalysis study." Mustafa Kemal Üniversitesi Sosyal Bilimler Enstitüsü Dergisi 12.32 (2015): 195220.

Üstündağ, Tülay. "Yaratıcı dramanın üç boyutu." (1996): 19-23.

Adıgüzel, Ö. (2006). Yaratıcı drama kavramı, bileşenleri ve aşamaları. Yaratıcı Drama Dergisi, 1(1), 17-30.

Ulubey, Ö., \& Toraman, Ç. (2015). Yaratıcı drama yönteminin akademik başarıya etkisi: bir metaanaliz çalışması/The effect of creative drama on students' academic achievement: A meta-analysis study. Mustafa Kemal Üniversitesi Sosyal Bilimler Enstitüsü Dergisi, 12(32), 195-220.

Selvi, K., \& Öztürk, A. (2000). Yaratıcı drama yöntemi ile fen öğretimi. Eğitim ve Bilim, 25(116).

Karasar, N. (2005). Bilimsel araştırma yöntemleri.

Baldwin, P., \& Fleming, K. (2003). Teaching literacy through drama: Creative approaches. Routledge.

Courtney, Richard. "Culture and the Creative Drama Teacher." Youth Theatre Journal 3.4 (1989): $18-23$.

Chalmers, Debbie. Drama 3-5: A practical guide to teaching drama to children in the foundation stage. Routledge, 2007. 